\title{
Prediction of Parental Combination for Introduction of Stay-green Associated Loci in Wheat ${ }^{1}$
}

\author{
Henrique de Souza Luche², José Antonio Gonzalez da Silva3, Rafael Nomberg4, Emilio Ghisleni Arenhardt5*, \\ Vanderlei da Rosa Caetano6, Luciano Carlos da Maia7, Antonio Costa de Oliveira8 \\ ${ }^{2}$ Senior Research Associate in the DuPont Pioneer, Sorriso-MT, Brazil. \\ ${ }^{3}$ Department of Agrarian Studies, Regional University of the Northwest of Rio Grande do Sul, Ijui, RS, Brazil \\ ${ }^{4}$ Breeder in OR Seeds, Passo Fundo-RS, Brazil. \\ ${ }^{5}$ PhD student in Department of Crop Plants, Federal University of Rio Grande do Sul, Porto Alegre, RS, Brazil \\ ${ }^{6}$ Research in Embrapa Temperate Agriculture, Pelotas-RS, Brazil. \\ ${ }^{7}$ Adjunct Professor in Center for Genomics and Plant Breeding, Faculty of Agronomy Eliseu Maciel, Federal University of Pelotas \\ ${ }^{8}$ Full Professor in Center for Genomics and Plant Breeding, Faculty of Agronomy Eliseu Maciel, Federal University of Pelotas
}

Received: December 10, 2016 / Revised: February 03, 2017 / Accepted: March 14, 2017

(C) Korean Society of Crop Science and Springer 2017

\begin{abstract}
In wheat, the increase of yield and stability associated traits can be achieved by combining parents containing the stay-green trait and favorable alleles for grain yield. The aim of this work was to analyze the genetic dissimilarity between wheat lines from stay-green and synchronized maturation groups and elite cultivars. Moreover, to propose promising combinations seeking the selection of high-grain yield and high bread-making quality genotypes containing stay-green trait. The experiment was conducted in a randomized block design with three replications in 2003, 2004, and 2005, using sister-lines with the presence and absence of stay-green trait and elite cultivars. Genetic variability exists among wheat strains from the synchronized stay-green maturation group and elite cultivars. Genotypes of maturation group stay-green obtained an average performance superior to the synchronized group. Crosses between stay-green lines and the CEP 29 and BRS 177 cultivars are promising in the selection of genotypes carrying the stay-green trait with high yield and bread-making quality.
\end{abstract}

Key words : Triticum aestivum L., yield grain, delayed senescence, genetic dissimilarity

\section{Introduction}

In the search for high yield associated with stability, wheat breeders have resorted to traits that promote greater efficiency in grain yield as increased harvest index and greater photosynthetic capacity. Among these alternatives, the increased photosynthetic efficiency or active leaf area for a longer period can be highlighted (Parry et al. 2011). Staygreen is characterized by retardation in leaf senescence favoring the maintenance of the photosynthetic apparatus (Thomas and Howarth 2000). It has achieved international recognition for its contribution to the greater stability of yields under environmental stress conditions (Kassahun et

Emilio Ghisleni Arenhardt $(\bowtie)$

Email: Brazil.emilio.arenhardt@yahoo.com.br

${ }^{1}$ Study done at the Center for Genomics and Plant Breeding, Faculty of Agronomy Eliseu Maciel, Federal University of Pelotas. al. 2010; Kumar et al. 2010). In southern Brazil, a significant contribution of stay-green trait for grain yield and abiotic stresses tolerance has been observed (Luche et al. 2013). The low complexity of stay-green i.e., its reduced number of genes can facilitate the breeder's work incorporate into elite genotypes, besides the great contribution involving high additive effects on inheritance (Joshi et al. 2007), a condition that favors the selection pressure in early generations in achieving significant genetic gains (Silva et al. 2008a).

Parental selection for crossing blocks is decisive in the formation of potential populations, denoting that some basic principles should be considered: i) parents with genetic dissimilarity: ii) high performance per se and: iii) combining ability (Benin et al. 2009). Thus, the genetic dissimilarity between high performance parents is crucial in the formation 
of transgressive segregants combining a large number of favorable alleles (Silva et al. 2007).

Currently, several wheat lines of different maturity groups developed by Brazilian breeding programs form part of their working collections, besides potential cultivars of high performance in yield and bread-making quality traits, such as BRS 177 and CEP 27, respectively. Thus, the identification of promising combinations with high performance genotypes for target traits and carrying the stay-green trait can contribute decisively to plant selection, since delayed leaf senescence associated with high yields and grain quality can contribute to genotype stability.

The aim of this work was to analyze the genetic dissimilarity between wheat lines from stay-green and synchronized maturation groups and elite cultivars. Moreover, to propose promising combinations seeking the selection of high-grain yield and high bread-making quality genotypes containing the stay-green trait.

\section{Material and Methods}

The study started from wheat genotypes with stay-green (TB438, carrying the stay-green trait) and non-stay-green (TB188, synchronized maturity) comprising selected lines by Embrapa Temperate Climate (Pelotas, RS, Brazil). These lines were obtained by recombination in recurrent selection with several other promising lines expressing the stay-green trait and others that showed synchronized senescence. Therefore, in 1998, crosses were made between these lines (TB438 $\times$ TB188) to obtain the $F_{1}$ generation, two backcross $\left(F_{1} \times\right.$ TB $438 ; F_{1} \times$ TB188) and $F_{2}$ populations by selfing of $F_{1}$. Through advances of $F_{2}$ to Fn generations, high-grain yield lines with differences in maturity were selected i.e., stay-green (SG) and synchronized (SZ). Moreover, the backcross populations $1\left[\mathrm{BC}_{1} \mathrm{~F}_{1}(\mathrm{P} 1 / / \mathrm{P} 1 / \mathrm{P} 2)\right]$ and $2\left[\mathrm{BC} \mathrm{F}_{1}(\mathrm{P} 2 / /\right.$ $\mathrm{P} 1 / \mathrm{P} 2)]$ were also subjected to self-pollination and selected for the presence and absence of the stay-green trait until highly homozygous.

It is noteworthy that in these populations, the selection also involved the simultaneous analyses for high-grain yield in the presence and absence of the stay-green trait. Therefore, in 2002, 14 lines of stay-green maturity group (SG30, SG39, SG47, SG53, SG65, SG71, SG74, BC1SG32, BC2SG34, BC2SG40, BC2SG46, BC2SG54, BC2SG62, BC2SG67, and TB438 parent) and 16 synchronized lines (SZ31, SZ37 SZ49, SZ57, SZ69, BC1SZ43, BC1SZ45, BC1SZ55, BC1SZ58, BC1SZ68, BC1SZ72, BC1SZ76, BC2SZ35, BC2SZ42, BC2SZ56, BC2SZ61, and TB188 parent) were obtained.

The experiments were conducted in 2003, 2004, and 2005 in the city of Capão do Leão/RS, being the soil classified Red Yellow Podzolic unit in Mapping Pelotas (Santos et al. 2006). The city is situated $31^{\circ} 52^{\prime} 00^{\prime \prime}$ south latitude and $52^{\circ}$ $21^{\prime} 24^{\prime \prime}$ west longitude; elevation of $13.24 \mathrm{~m}$, with an average annual rainfall of $1280.2 \mathrm{~mm}$. Stay-green and synchronized lines were evaluated along with BRS 177 (high-grain yield cultivar) and CEP 27 (high bread-making quality cultivar). A randomized block design with three replications was used where each experimental unit was formed by plots with five $3.0-\mathrm{m}$-long rows spaced in $0.20 \mathrm{~m}$, adopting a density of 300 viable seeds per $\mathrm{m}^{-2}$. The fertilization and liming were based on technical recommendations for the crop, according to the results of the soil analysis. Cultural practices, as well as weed, disease, and pest control were also carried out according to the technical recommendations for the crop.

The evaluated traits were the grain yield $\left(\mathrm{GY}, \mathrm{kg} \mathrm{ha}^{-1}\right)$ obtained from the yield value of the dimensioned plot for hectare; thousand grain weight (TGW, g) by 250 grain counting with subsequent weighing and multiplied by four; fertile tillers number (FTN, units) by counting the center line of 1 meter from both ends of the plot divided by two; grain number per ear (GNE, units) the average value obtained from the random collection of ten ears in each plot in the main tiller. From the average of the same 10 ears in each plot the ear weight (EW, g); grain weight per ear (GWE, g), ear length (EL, cm), spikelet fertility number (SFN, units), and harvest index per ear (HIE, $\mathrm{g} \mathrm{g}^{-1}$ ), obtained by the ratio between the grain weight per ear and total ear weight, were calculated.

The data were subjected to analysis of variance for the detection of the main effects and interaction between sources of variation year and genotypes on the direct yield trait and those linked to wheat inflorescence. After, a mean comparison using Scott and Knott test aiming to cluster genetic differences by the mean effect of the three years of the evaluation was held. Based on the means, the estimate of genetic dissimilarity among wheat genotypes using generalized Mahalanobis distance $\left(D^{2}\right)$ was held. From the distance matrix generated, the grouping of genotypes and the relative contribution analysis of the variables were made by Tocher method and according to the model proposed by Singh, respectively. All procedures and analyses were run on the GENES software (Cruz 2013).

\section{Results and Discussion}

The summary of variance analysis in Table 1 shows the existence of differences in the genotype source of variation for all evaluated traits, suggesting the possibility of identifying genetic constitutions of enhanced performance per se on the direct yield traits and those that compose the wheat inflorescence.

It is emphasized that even identified the presence of interaction, the analysis proceeded to have as proposed to detect genetic differences by the average effect of the three years of evaluation (Table 1). Therefore, the grain yield trait (GY) two distinct classes have been observed. In such, the BRS177 and CEP27 cultivars (controls) together with staygreen (except $\mathrm{BC} 2 \mathrm{SG} 67$ ) and the $\mathrm{BC} 1 \mathrm{SZ68}$ synchronized maturation lines exhibit superior performance per se to compose the group "a". The formation of groups for grain yield showed that most of the genotypes carrying stay-green 
trait demonstrated higher average performance than the group of synchronized lines, suggesting an association between the introduced trait and grain yield increases (De La

Vega et al. 2011; Jordan et al. 2012; Luche et al 2013; Parry

Table 1. Summary of the analysis of variance and mean comparison of the wheat genotypes stay-green and synchronized maturity group for the yield and inflorescence traits.

\begin{tabular}{|c|c|c|c|c|c|c|c|c|c|}
\hline \multirow{2}{*}{ Traits } & \multicolumn{7}{|c|}{ Mean Square } & \multirow{2}{*}{ Means } & \multirow{2}{*}{ CV (\%) } \\
\hline & \multicolumn{2}{|c|}{ Genotype } & \multicolumn{2}{|l|}{ Year } & $G \times Y$ & \multicolumn{2}{|c|}{ Error } & & \\
\hline GY & \multicolumn{2}{|c|}{$760962^{* *}$} & \multicolumn{2}{|l|}{$18144012^{* *}$} & $297290^{* *}$ & \multicolumn{2}{|c|}{62570} & 2031 & 12.31 \\
\hline TGW & \multicolumn{2}{|c|}{$21.88^{* *}$} & \multicolumn{2}{|l|}{$265.68^{* *}$} & \multicolumn{2}{|l|}{$18.72^{* *}$} & 5.03 & 34.66 & 6.47 \\
\hline FTN & \multicolumn{2}{|c|}{$562.88^{* *}$} & \multicolumn{2}{|l|}{$5242.00^{* *}$} & \multicolumn{2}{|l|}{$160.82^{* *}$} & 100.68 & 63.07 & 15.91 \\
\hline GNE & \multicolumn{2}{|c|}{$120.77^{* *}$} & \multicolumn{2}{|l|}{$10695.00 * *$} & $59.73^{* *}$ & & & 50.31 & 11.10 \\
\hline EW & 0.3 & & $36.01^{* *}$ & & $0.16^{* *}$ & & & 2.66 & 12.14 \\
\hline GWE & 0.1 & & $25.82^{* *}$ & & $0.09^{* *}$ & & & 1.81 & 14.48 \\
\hline EL & 6.7 & & $41.24^{* *}$ & & 3.06 & & & 11.34 & 13.83 \\
\hline SFN & 6.6 & & $64.51^{* *}$ & & $2.72^{* *}$ & & & 20.05 & 6.78 \\
\hline HIE & 0.0 & & $0.22^{* *}$ & & 0.01 & & & 0.67 & 8.01 \\
\hline linos & & & & Gene & Means 201 & 2012 & & & \\
\hline Limes & GY (kg ha) & $\operatorname{TGW}(\mathrm{g})$ & NFT (n) & NGE (n) & WE $(g)$ & WGE $(\mathrm{g})$ & $\mathrm{EL}(\mathrm{cm})$ & NFS (n) & HIE \\
\hline TB438 & $2134+a$ & $34.71 a$ & $64 c$ & $57 a$ & $2.67 \mathrm{~b}$ & $1.92 a$ & $11.46 a$ & $21.0 a$ & $0.72 a$ \\
\hline SG30 & $2143 a$ & $33.60 \mathrm{~b}$ & $59 d$ & $51 a$ & $2.52 b$ & $1.75 a$ & $10.72 b$ & $20.4 a$ & $0.68 \mathrm{a}$ \\
\hline SG39 & $2349 a$ & $31.99 b$ & $68 c$ & $55 a$ & $2.55 b$ & $1.80 \mathrm{a}$ & $10.62 b$ & $20.0 a$ & $0.70 a$ \\
\hline SG47 & $2394 a$ & $34.79 a$ & $63 c$ & $50 a$ & $2.48 b$ & $1.75 a$ & $10.64 b$ & $20.8 a$ & $0.68 a$ \\
\hline SG53 & $2587 a$ & $36.07 a$ & $68 c$ & $53 a$ & $2.47 \mathrm{~b}$ & $1.80 \mathrm{a}$ & $10.34 b$ & $19.4 a$ & $0.72 a$ \\
\hline SG65 & $2320 a$ & $35.72 a$ & $62 d$ & $52 a$ & $2.52 \mathrm{~b}$ & $1.80 \mathrm{a}$ & $10.50 \mathrm{~b}$ & $20.4 a$ & $0.70 a$ \\
\hline SG71 & $2477 a$ & $35.08 a$ & $64 c$ & $54 a$ & $2.66 \mathrm{~b}$ & $1.90 a$ & $10.90 \mathrm{~b}$ & $20.7 a$ & $0.70 a$ \\
\hline SG74 & $2308 a$ & $35.32 \mathrm{a}$ & $65 c$ & $51 a$ & $2.52 b$ & $1.79 a$ & $10.19 b$ & $20.0 a$ & $0.70 a$ \\
\hline BC1SG32 & $2278 a$ & $33.44 b$ & $61 d$ & $53 a$ & $2.58 b$ & $1.81 \mathrm{a}$ & $10.59 \mathrm{~b}$ & $20.1 \mathrm{a}$ & $0.70 a$ \\
\hline BC2SG34 & $1934 b$ & $34.37 a$ & $60 d$ & $52 a$ & $2.76 a$ & $1.91 a$ & $11.31 a$ & $20.4 a$ & $0.70 a$ \\
\hline BC2SG40 & $2087 a$ & $33.43 b$ & $66 c$ & $51 a$ & $2.63 b$ & 1.83a & $11.42 \mathrm{a}$ & $20.0 a$ & $0.69 a$ \\
\hline BC2SG46 & $2062 a$ & $36.35 a$ & $61 d$ & $51 a$ & $2.74 b$ & $1.86 a$ & $11.97 a$ & $20.4 a$ & $0.68 a$ \\
\hline BC2SG54 & $2164 a$ & $34.21 a$ & $57 d$ & $47 b$ & $2.61 b$ & $1.80 \mathrm{a}$ & $11.39 a$ & $19.9 a$ & $0.70 a$ \\
\hline BC2SG62 & $2300 a$ & $34.75 a$ & $63 c$ & $52 a$ & $2.64 b$ & $1.86 a$ & $11.48 a$ & $20.8 a$ & $0.70 a$ \\
\hline BC2SG67 & $2014 b$ & $36.89 a$ & $60 d$ & $54 a$ & $2.71 b$ & $1.84 a$ & $11.97 a$ & $20.3 a$ & $0.67 \mathrm{~b}$ \\
\hline TB188 & 1616b & 35.03a & $70 c$ & $46 b$ & $2.62 \mathrm{~b}$ & $1.75 a$ & $10.31 \mathrm{~b}$ & $19.0 \mathrm{~b}$ & $0.65 b$ \\
\hline SZ31 & $1854 b$ & $32.97 \mathrm{~b}$ & $64 c$ & $47 b$ & $2.61 b$ & $1.66 \mathrm{~b}$ & $14.18 a$ & $19.7 a$ & $0.63 b$ \\
\hline SZ37 & $1838 b$ & $34.37 a$ & $66 c$ & $49 b$ & $2.71 b$ & $1.80 a$ & $11.88 a$ & $19.7 a$ & $0.66 \mathrm{~b}$ \\
\hline SZ49 & $1652 b$ & $35.40 a$ & $58 d$ & $53 a$ & $2.91 a$ & $1.92 a$ & $12.37 a$ & $20.3 a$ & $0.65 b$ \\
\hline SZ57 & $1706 \mathrm{~b}$ & $33.87 \mathrm{~b}$ & $60 d$ & $51 a$ & $2.89 a$ & 1.88a & $12.02 \mathrm{a}$ & $20.1 \mathrm{a}$ & $0.64 b$ \\
\hline SZ69 & $1932 b$ & $31.81 \mathrm{~b}$ & $67 c$ & $46 b$ & $2.59 b$ & $1.68 b$ & $11.71 \mathrm{a}$ & $19.2 b$ & $0.64 b$ \\
\hline BC1SZ43 & 1973b & $32.90 \mathrm{~b}$ & $58 d$ & $53 a$ & $2.57 \mathrm{~b}$ & $1.79 a$ & $11.17 \mathrm{~b}$ & $20.9 a$ & $0.68 a$ \\
\hline BC1SZ45 & $1727 b$ & $32.96 \mathrm{~b}$ & $55 d$ & $51 a$ & $2.85 a$ & $1.80 \mathrm{a}$ & 12.30a & $21.1 \mathrm{a}$ & $0.62 b$ \\
\hline BC1S Z55 & $1569 b$ & $35.42 a$ & $61 d$ & $53 a$ & $3.09 a$ & $1.95 a$ & $12.44 a$ & 21.3a & $0.63 b$ \\
\hline BC1SZ58 & $1861 \mathrm{~b}$ & $35.68 a$ & $55 d$ & $47 b$ & $2.73 b$ & $1.79 a$ & $11.86 a$ & $20.0 a$ & $0.65 b$ \\
\hline BC1SZ68 & $2278 a$ & $35.98 a$ & $73 c$ & $43 c$ & $2.36 b$ & $1.65 b$ & $10.56 \mathrm{~b}$ & $18.6 \mathrm{~b}$ & $0.70 a$ \\
\hline BC1SZ72 & $1719 b$ & $35.24 a$ & $59 d$ & $51 a$ & $2.85 a$ & $1.84 a$ & $12.33 a$ & $20.7 a$ & $0.64 b$ \\
\hline BC1SZ76 & $1749 b$ & $36.44 a$ & $62 d$ & $52 a$ & $3.04 a$ & $2.04 a$ & $11.78 \mathrm{a}$ & $20.6 a$ & $0.67 \mathrm{~b}$ \\
\hline BC2SZ35 & $1812 b$ & $33.53 b$ & $60 d$ & $48 b$ & $2.68 \mathrm{~b}$ & $1.82 \mathrm{a}$ & $11.33 a$ & $20.0 a$ & $0.68 a$ \\
\hline BC2SZ42 & $1825 b$ & $35.00 a$ & $56 d$ & $49 b$ & $2.59 b$ & $1.73 a$ & $11.07 \mathrm{~b}$ & $20.0 a$ & $0.67 b$ \\
\hline BC2SZ56 & $1652 b$ & $34.70 a$ & $55 d$ & $49 b$ & $2.86 a$ & 1.88a & $10.81 \mathrm{~b}$ & $19.9 a$ & $0.65 b$ \\
\hline BC2SZ61 & $1853 b$ & $38.15 a$ & $52 d$ & $53 a$ & $3.02 a$ & 2.03a & $11.46 a$ & $20.3 a$ & $0.66 \mathrm{~b}$ \\
\hline BRS 177 & $2414 a$ & $31.11 b$ & $93 a$ & $40 c$ & $2.07 \mathrm{~b}$ & $1.48 \mathrm{c}$ & $9.73 b$ & $16.9 c$ & $0.72 a$ \\
\hline CEP 27 & $2491 a$ & $37.07 a$ & $81 b$ & $44 \mathrm{c}$ & $2.58 \mathrm{~b}$ & 1.86a & $10.60 \mathrm{~b}$ & $18.6 \mathrm{~b}$ & $0.72 \mathrm{a}$ \\
\hline
\end{tabular}

+ Means followed by the same letter in the column do not differ at $5 \%$ probability of error by Scott-Knott test; ${ }^{*}$ significant at 1 error probability by $\mathrm{F}$ test; $\mathrm{CV}=$ coefficient of variation; GY = grain yield; TGW = thousand-grain weight; FTN = fertile tillers number; $G N E=$ grain number per ear; $E W=$ ear weight; $G W E=$ grain weight per ear; EL = ear length; SFN = spikelet fertility number; HIE = harvest index per ear; SG = Line stay-green; $\mathrm{SZ}$ = Lines synchronized. 
et al. 2011; Silva et al. 2008a). Although the stay-green trait itself was no guarantee of superiority for grain yield, as it happened with delayed senescence line BC2SG67, that was integrated into the lower performance group "b". The same happened with the synchronized senescence line BC1SZ68, which was placed among those of group "a". Thus, combining the stay-green gene and favorable alleles provides a genotypic synergism. These considerations were also observed by (Silva et al. 2008a), pointing out that the removal of grain yield plateaus can be achieved by using the stay-green trait in wheat populations that show accumulation of alleles of interest.

In the variable thousand-grain weight (TGW), the distribution of the averages of genotypes resulted in two distinct classes (Table 1). It is noteworthy that from the 22 genotypes that make up the class "a", 11 are lines of stay-green maturity group, 10 of the synchronized group and the CEP 27 cultivar. An odd observation was the similar ratio of lines from different maturity groups, suggesting that the expression of TGW is not the exclusive trait in increasing yield in the genotypes with delayed senescence. This fact comes to disagree with reports that describe the direct influence of the stay-green gene on thousand grain weight increases (Ahlawat et al. 2008). On the other hand, Silva et al. (2005), evaluating populations of stay-green and synchronized wheat found, by path analysis, indirect effects from thousand-grain weight on grain yield via grain number per ear and spikelet fertility number. These results indicate that the stay green condition is also connected to other traits, influencing indirect effects on the components of grain yield. The stay-green trait promoted an increase in grain yield by increased floret fertile in the base of the ear, which resulted in the increase of grain number (Luche et al. 2013).

For the variable fertile tillers number (FTN), only BRS177 indicated superior performance "a" (Table 1). This confirms the potential contribution of this cultivar as a source of favorable alleles to increase fertile tiller capacity. Tillering is an important trait associated with adaptation to unfavorable environments, besides representing one of the most important direct components of the GY. This condition strengthens the use of BRS 177 as a potential parental in wheat crossing blocks (Valério et al. 2009).

The variable grain number per ear (GNE) indicated a high performance of the stay-green group lines, with the only exception of the BC2SG54 line that did not integrate the superior performance group "a" (Table 1). The GNE is a yield component strongly stimulated by the availability of nitrogen to the plant (Acreche and Slafer 2006). Thus, the presence of the stay-green trait is said to increase the concentration of cytokinins in leaves and stems, promoting nutrient concentration, among them the nitrogen that stimulates and favors the formation of spikelet fertility number per ear (Masclaux et al. 2001). Therefore, the maintenance of photosynthetic rate of leaves and stems is reflecting in the increase the grain number per ear of wheat (Ahlawat et al. 2008). This reinforces what was discussed earlier, indicating that the reduced influence of the stay-green trait in maximizing the TGW is offset by the increase in the grain number per ear. In the ear weight (EW), eight synchronized lines and one stay-green formed the higher group "a". Similarly, to the ear length (EL), 12 of the 19 highlighted genotypes were part of the synchronized group. This fact lifts the hypothesis that the stay-green trait can be associated with a smaller size ear. However, regarding grain weight per ear (GWE) and ear weight for obtaining the harvest index per ear (HIE), the stay-green genotypes were more efficient in the partitioning of assimilates directed to the grain, because, from a total of 19 superior lines ranked as "a", 14 are part of the stay-green maturity group. Higher capacity of grain filling and/or grain ear in the stay-green genotypes compared to normal maturation were found (Silva et al. 2003), which explains the superiority in HIE for those lines with higher stay-green genes. However, both the grain weight per ear and the spikelet fertility number (SFN) indicated a similar proportion between the lines of different maturity groups (Table 1).

From the average effect of the three years of evaluation, matrices of genetic dissimilarity were obtained by the Mahalanobis model and later built the genetic distance groups by Tocher method (Table 2). In this method, the formation of groups scales the greatest similarity between the genotypes in the group and the dissimilarity when in different groups (Cruz et al. 2004). In the stay-green maturity group, the formation of seven distinct groups was observed (Table 2). The group I was composed by SG30, SG47, SG65, SG71, SG74, and the BC1SG32 lines, deriving from a backcross with the stay-green parent (TB438). However, groups II (BC2SG34, BC2SG40, BC2SG62), III (BC2SG46, BC2SG67), and IV (BC2SG540) were obtained by backcrossed lines with the synchronized parent (TB188). Group V was composed of TB438 (stay-green parent) and groups VI and VII by the SG53 and SG39 lines, respectively. It was observed the formation of a larger number of groups among wheat lines stay-green than lines synchronized maturation, revealing the existence of greater variability. This way, the possibility crosses between stay-green lines of the group different can increment the recombination of alleles favorable with presence stay-green traits The stay-green trait was shown to be controlled by a small number of genes with additive effects (Joshi et al. 2007; Kumar et al. 2010; Silva et al. 2001). However, CukadarOlmedo and Miller (1997) found the strong contribution of the interaction between additive and dominant epistatic effects in the inheritance of stay-green trait in sunflower. The strong synteny found between regulatory regions of this trait in the different species studied (Sato et al. 2007; Srinivas et al. 2008) suggests that the combination of the stay-green group parents can lead to breakage of genic blocks associated with delayed maturation, eliminating non-additive effects (epistatic) and leading to increased expression of the stay-green plant. In the synchronized pattern genotypes (Table 2), four groups were obtained. Group I was composed of the synchronized parent and 13 lines obtained from selfing or backcrossing with subsequent selfing (TB188, SZ49, BC1SZ72, SZ57, 
Table 2. Grouping lines of stay-green (SG) and synchronized (SZ) maturity group of yield traits and wheat inflorescence made by the Tocher method, based on the Mahalanobis distance $\left(D^{2}\right)$.

\begin{tabular}{|c|c|c|c|c|c|c|}
\hline \multirow{2}{*}{$\frac{\text { Group }}{1}$} & \multicolumn{6}{|c|}{ Lines stay-green (SG) } \\
\hline & SG30 & RC1SG32 & SG47 & SG71 & SG65 & SG74 \\
\hline$\|$ & RC2SG34 & RC2SG40 & RC2SG62 & & & \\
\hline III & RC2SG46 & RC2SG67 & & & & \\
\hline IV & RC2SG54 & & & & & \\
\hline V & TB438 & & & & & \\
\hline $\mathrm{Vl}$ & SG53 & & & & & \\
\hline $\mathrm{VII}$ & SG39 & & & & & \\
\hline Group & \multicolumn{6}{|c|}{ Lines synchronized (SZ) } \\
\hline \multirow{3}{*}{ I } & SZ49 & RC1SZ72 & SZ57 & SZ37 & RC1SZ76 & RC2SZ56 \\
\hline & RC2SZ35 & RC1SZ58 & RC2SZ42 & RC1SZ45 & RC1S Z55 & RC2SZ61 \\
\hline & SZ69 & TB188 & & & & \\
\hline$\|$ & SZ31 & & & & & \\
\hline III & RC1SZ43 & & & & & \\
\hline IV & RC1SZ68 & & & & & \\
\hline Group & \multicolumn{6}{|c|}{ Lines SG + SZ } \\
\hline \multirow{4}{*}{ I } & SZ49 & RC1SZ72 & SZ57 & RC1SZ76 & RC2SZ56 & RC1SZ58 \\
\hline & SZ37 & RC2SZ35 & RC2SZ42 & RC2SG34 & RC2SG46 & RC2SG40 \\
\hline & RC1SZ45 & RC2SG67 & RC1SZ55 & RC2SZ61 & RC2SG54 & SG30 \\
\hline & RC1SZ43 & RC2SG62 & & & & \\
\hline \multirow{2}{*}{$\|$} & SG65 & SG74 & SG47 & SG71 & RC1SG32 & SG53 \\
\hline & TB438 & SG39 & & & & \\
\hline III & SZ31 & SZ69 & & & & \\
\hline IV & TB188 & & & & & \\
\hline V & RC1SZ68 & & & & & \\
\hline Group & \multicolumn{6}{|c|}{ Lines SG + SZ + Elite cultivars } \\
\hline \multirow{6}{*}{ I } & SZ49 & RC1SZ72 & SZ57 & SZ37 & RC1SZ76 & RC2SZ56 \\
\hline & RC1SZ58 & RC2SZ35 & RC2SZ42 & RC2SG34 & $\mathrm{RC} 2 \mathrm{SG} 46$ & RC2SG40 \\
\hline & RC1SZ45 & RC2SG67 & RC1S Z55 & RC2SZ61 & SZ69 & RC2SG54 \\
\hline & SG30 & RC1SZ43 & RC2SG62 & RC1SG32 & SG74 & SG65 \\
\hline & SG47 & SG71 & TB438 & TB188 & RC1SZ68 & SG39 \\
\hline & SG53 & SZ31 & & & & \\
\hline$\|$ & CEP 27 & & & & & \\
\hline III & BRS 177 & & & & & \\
\hline
\end{tabular}

SZ37, BC1SZ76, BC2SZ56, BC2SZ35, BC1SZ58, BC2SZ42, BC1SZ45, BC1SZ55, and BC2SZ61). Groups II (SZ31), III (BC1SZ43), and IV (BC1SZ68) were formed by isolated lines. Of these, superiority was noted in the BC1SZ68 line, presenting the best performance among the rest of the synchronized group, mainly by high yield and thousand-grain weight (Table 1). Its emphasized that this structure is also interesting, showing a detailed analysis of the pattern of synchronized elite genotypes, the source of favorable alleles for use of the breeder. Still, the possibility of synchronized germplasm use selected for lowland conditions in new crosses with genotypes of superior performance to yield components together with the genes encoding delayed maturation. In wheat, Bertan et al. (2009) commented that information on the phenotypic expression and genetic distance between parents likely allows enhancing genetic variability of the species, promoting the directing efforts in populations most likely to prospecting superior lines. Also, the greater possibility of recombining distinct alleles resulted in an increased range of genotypic classes that will be obtained in the population of selection $\left(\mathrm{F}_{2}\right.$ generation). The success in selecting germplasm for the breeding program requires a set of lines with different sources of alleles for traits of interest for breeders (Nass and Paterniani 2000).

In the joint analysis (lines of stay-green and synchronized maturation group), five distinct groups were obtained. Group 
I was composed both by synchronized as stay-green lines, but a great frequency of lines with synchronized maturity group, either by selfing as from the $F_{1}$ or backcrossed by one generation with stay-green and synchronized parent (SZ49, BC1SZ72, SZ57, BC1SZ76, BC2SZ56, BC1SZ58, SZ37, BC2SZ35, BC2SZ42, BC2SG34, BC2SG46, BC2SG40, BC1SZ45, BC2SG67, BC1SZ55, BC2SZ61, BC2SG54, SG30, BC1SZ43, and BC2SG62). Group II was represented only by stay-green lines, including the delayed maturation parent (SG65, SG 74, SG 47, SG 71, BC1SG32, SG53, TB438, and SG39). Group III, however, was composed only of synchronized type lines (SZ 65 and SZ 69). The group IV was only represented by synchronized parent (TB 188) and the group $\mathrm{V}$, by the synchronized line with superior grain yield (BC1SZ68). In Table 2, the set of lines for both maturity groups certifies the contribution of these parents for the observed genetic variability, is the type of maturation or other traits analyzed. The composition of group I, with a strong influence of synchronized parent (TB 188), confirms that the differences between lines are more restricted to their maturity group. In addition, the $\mathrm{BC} 1 \mathrm{SZ} 68$ line, besides presenting high-grain yield, was genetically distant from the other synchronized and stay-green lines. The high performance and dissimilarity of synchronized lines show the importance of crosses seeking recombination and accumulation of alleles focused on grain yield (Luche et al. 2013). Although the stay-green trait provides advantages to the normal maturation, the accumulation of favorable alleles for grain yield is decisive for the selection of superior genotypes (Silva et al. 2008a).

In the analysis involving all lines of different maturity groups and elite cultivars (Table 2), the formation of three distinct groups was obtained. Group I was formed by all the stay-green and synchronized maturation lines, including the parents (TB438 and TB188). The group II was formed by BRS 177 and group III, only by CEP 27 . The composition of group I showed that the distance between all the lines is small when compared to commercial genotypes, regardless of the maturation type. Therefore, a condition which highlights that the absence or presence of the stay-green trait itself was not sufficient for the formation of distinct groups between lines of different maturity groups. The cross between similar parents does not promote the onset of transgressive individuals by the difficulty of having alleles of complementary nature (Vieira et al. 2007). The complementarity in autogamous can be translated into greater vigor hybrid in the $F_{1}$ generation and consequent increase in the number of selection classes in the $\mathrm{F}_{2}$ generation (Bertan et al. 2009). The observation of performance per se of the genotypes (Table 1), together with the variability detected by the Tocher method (Table 2) indicated that CEP 27 and BRS 177 cultivars were promising genotypes in the composition of crossing blocks with wheat lines of different maturity

Table 3. Summary of relative contribution analysis on the yield and inflorescence traits of the wheat lines of stay-green (SG) and synchronized (SZ) maturation group by Singh method.

\begin{tabular}{|c|c|c|c|c|}
\hline \multirow{2}{*}{ Variable } & \multicolumn{2}{|c|}{ Relative Contribution (SG) } & \multicolumn{2}{|c|}{ Relative Contribution (SZ) } \\
\hline & S.j & Value in \% & S.j & Value in \% \\
\hline GY & 52.16 & 11.48 & 58.09 & 11.81 \\
\hline TGW & 43.79 & 9.64 & 85.52 & 16.98 \\
\hline FTN & 21.91 & 4.82 & 76.19 & 15.49 \\
\hline GNE & 81.16 & 17.87 & 52.86 & 10.75 \\
\hline EW & 64.23 & 14.14 & 44.42 & 9.03 \\
\hline GWE & 21.01 & 4.62 & 36.43 & 7.41 \\
\hline EL & 139.64 & 30.74 & 38.12 & 7.75 \\
\hline SFN & 20.56 & 4.53 & 47.68 & 9.69 \\
\hline HIE & 9.83 & 2.16 & 54.53 & 11.09 \\
\hline \multirow{2}{*}{ Variable } & \multicolumn{4}{|c|}{ General Relative Contribution (SG + SZ) } \\
\hline & \multicolumn{2}{|c|}{ S.j } & \multicolumn{2}{|c|}{ Value in \% } \\
\hline GY & \multicolumn{2}{|c|}{569.97} & \multicolumn{2}{|c|}{22.9} \\
\hline TGW & \multicolumn{2}{|c|}{251.25} & \multicolumn{2}{|c|}{10.09} \\
\hline FTN & \multicolumn{2}{|c|}{197.72} & \multicolumn{2}{|c|}{7.94} \\
\hline GNE & \multicolumn{2}{|c|}{418.04} & \multicolumn{2}{|c|}{16.79} \\
\hline EW & \multicolumn{2}{|c|}{176.11} & \multicolumn{2}{|c|}{7.07} \\
\hline GWE & \multicolumn{2}{|c|}{21.3} & \multicolumn{2}{|c|}{0.86} \\
\hline$E L$ & \multicolumn{2}{|c|}{262.28} & \multicolumn{2}{|c|}{10.54} \\
\hline SFN & \multicolumn{2}{|c|}{160.06} & \multicolumn{2}{|c|}{6.43} \\
\hline HIE & \multicolumn{2}{|c|}{432.67} & \multicolumn{2}{|c|}{17.38} \\
\hline
\end{tabular}

GY = grain yield; TGW = thousand-grain weight; FTN = fertile tillers number; GNE = grain number per ear; EW = ear weight; GWE = grain weight per ear; EL = ear length; SFN = spikelet fertility number; HIE = harvest index per ear; S.j= relative contribution. 
groups. Although commercial genotypes were subjected to intense selection pressure and tests in different environments, the elite cultivars tested bring with them the possibility of complementarity with the introduction of grain yield and grain quality alleles when crossed with lines of the stay-green group. Therefore, can promote selection of plants with genes of interest associated with the benefits the largest stay-green of wheat plant (Silva et al. 2005).

In an analysis that seeks the differentiation of genotypes in groups, clarity of the contribution of the variables on the evaluated genetic variability is important (Silva et al. 2008b). Thus, the contribution of the traits to the genetic dissimilarity was carried out by the Singh model, either generally or isolated for both maturity groups (Table 3).

In stay-green genotypes, the ear length was the largest contributor to the differences between lines (30.74\%), followed by grain number per ear $(17.87 \%)$, ear weight $(14.14 \%)$, grain yield (11.48\%), and thousand-grain weight (9.64\%). In the synchronized lines traits with highlighted contributions were not observed. This condition evidences a greater adjustment in the proportion of traits that promote variability in this group. In the condition combined (stay-green and synchronized) (Table 3 ) the contribution of the traits grain yield $(22.9 \%)$, harvest index per ear $(17.38 \%)$, and grain number per ear $(16.79 \%)$ to the total difference between the lines is evident, possibly linked to the largest green permanency of stay-green trait of the expression of grain number per ear and the harvest index per ear, as observed in Table 1. Luche et al. (2013) found a strong contribution to the yield and grain number per ear on the variability of stay-green lines, a fact confirmed by Ahlawat et al (2008) in wheat with stronger stay-green phenotypes. The strong contribution of harvest index per ear for the total difference observed between the genotypes may be linked to greater grain number per ear found in lines carrying the stay-green traits at the expense of the lower ear length (Table 1). However, the results observed on the benefits of stay-green trait suggest the possibility of sequencing these genes by designing primers aimed at markerassisted selection for the maturity group.

\section{Conclusions}

Exist genetic variability among wheat strains from the synchronized stay-green maturation group and elite cultivars. Genotypes of maturation group stay-green obtained an average performance superior to the synchronized group.

Crosses between stay-green lines and the CEP 29 and BRS 177 cultivars are promising in the selection of genotypes carrying the stay-green trait with high yield and bread-making quality.

\section{Acknowledgements}

To CNPq, FAPERGS, CAPES, UFPEL, and UNIJUÍ by the contribution of resources to the development of this research and by grants for Scientific and Technological Initiation and Research Productivity.

\section{References}

Acreche MM, Slafer GA. 2006. Grain weight response to increases in number of grains in wheat in a Mediterranean area. Field Crop. Res. 98: 52-59

Ahlawat S, Chhabra AK, Behl RK, Bisht SS. 2008. Genotypic divergence analysis for stay green characters in wheat (Triticum aestivum L. em. Thell). SPJNAS 26: 73-81

Benin G, Silva GO, Pagliosa ES, Lemes C, Signorini A, Beche E, Capelin MA. 2009. Capacidade de combinação em genótipos de trigo estimada por meio de análise multivariada. Pesqui. Agropecu. Bras. 44: 1145-1151

Bertan I, Carvalho FIF, Costa de Oliveira A, Silva JAG, Benin G, Hartwig I, Schimidt DAM, Valério IP, Fonseca DAR, Silveira G. 2009. Efeitos da heterose e endogamia em caracteres de importância agronômica em trigo. Rev. Ceres. 56: 6, 753-763

Cruz CD, Regazzi AJ, Carneiro PCS. 2004. Modelos biométricos aplicados ao melhoramento genético: v1. 3 ed. Viçosa: UFV, $480 \mathrm{pp}$

Cruz CD. 2013. GENES - A software package for analysis in experimental statistics and quantitative genetics. Acta Sci-Agron. 35: 271-276

Cukadar-Olmedo B, Miller JF. 1997. Inheritance of the stay-green trait in sunflower. Crop Sci. 37: 1, 150-153

De La Vega AJ, Cantore MA, Sposaro MM, Trápani N, López Pereira M, Hall AJAJ. 2011. Canopy stay-green and yield in non-stressed sunflower. Field Crop. Res. 121: 175-185

Jordan DR, Hunt CH, Cruizkshank AW, Borrell AK, Henzell RG. 2012. The relationship between the stay-green trait and grain yield in elite sorghum hybrids grown in a range of environments. Crop Sci. 52: 1153-1161

Joshi AK, Kumari M, Singh VP, Reddy CM, Kumar S, Rane J, Chand R. 2007. Stay green trait: variation, inheritance and its association with spot blotch resistance in spring wheat (Triticum aestivum L.). Euphytica 153: 59 -71

Kassahun B, Bidinger FR, Hash CT, Kuruvinashetti MS. 2010. Stay-green expression in early generation sorghum [Sorghum bicolor (L.) Moench] QTL introgression lines. Euphytica 172: 351-362

Kumar U, Joshi AK, Kumari M, Paliwal R, Kumar S, Röder MS. 2010. Identification of QTLs for stay green trait in wheat (Triticum aestivum L.) in the 'Chirya 3' $\times$ 'Sonalika' population. Euphytica 174: 437-445

Luche HS, Silva JAG, Nornberg R, Silveira SFS, Baretta D, Groli EL, Maia LC, Costa de Oliveira A. 2013. Desempenho per se e parâmetros genéticos de linhagens de trigo com expressão do caráter "stay-green". Pesqui. Agropecu. Bras. 48: 167-173

Nass LL, Paterniani E. 2000. Pre-breeding: a link between genetic resources and maize breeding. Sci. Agric. 57: 3

Parry MAJ, Reynolds M, Salvucci ME, Raines C, Andralojc J. 
2011. Raising yield potential of wheat. II. Increasing photosynthetic capacity and efficiency. J. Exp. Bot. 62: 453-467

Santos HG, Jacomine PKT, Anjos LHC, Oliveira VA, Oliveira JB, Coelho MR, Lumbreras JF, Cunha TJF. 2006. Sistema brasileiro de classificação de solos. Rio de Janeiro: Embrapa Solos $306 \mathrm{pp}$

Sato Y, Morita R, Nishimura M, Yamaguchi H, Kusaba M. 2007. Mendel's green cotyledon gene encodes a positive regulator of the chlorophyll-degrading pathway. PNAS. 104: 14169-14174

Silva AS, Carvalho FIF, Nedel JL, Cruz PJ, Silva JAG, Caetano, VR, Hartwig I, Sousa CS. 2005. Análise de trilha para os componentes de rendimento de grãos em trigo. Bragantia 64: 191-196

Silva GO, Pereira AS, Souza VQ, Carvalho FIF, Costa de Oliveira A, Bertan I, Fritsche Neto R. 2008b. Importância de caracteres na dissimilaridade de progênies de batata em gerações iniciais de seleção. Bragantia 67: 141-144

Silva JAG, Carvalho FIF, Hartwig I, Caetano VR, Bertan I, Maia LC, Schimidt DAM, Finatto T, Valério IP. 2007. Distância morfológica entre genótipos de trigo com ausência e presença do caráter "stay-green". Cienc. Rural. 37: 1261-1267

Silva JAG, Carvalho FIF, Hartwig I, Oliveira AC, Bertan I, Caetano VR, Schmidt DAM, Valério IP, Ribeiro G, Busato CC. 2008a. Caráter stay-green e produtividade de grãos em trigo. Bragantia 67: 161-167

Silva SA, Carvalho FIF, Caetano VR, Oliveira AC, Coimbra JLM, Vasconcellos NJM, Lorencetti C. 2001. Genetic basis of stay-green trait in bread wheat. J. New Seeds 2: 55-58

Silva SA, Carvalho FIF, Nedel JL, Cruz PJ, Peske ST, Simioni D, Cargnin A. 2003. Enchimento de sementes em linhas quase isogênicas de trigo com presença e ausência do caráter "staygreen". Pesqui. Agropecu. Bras. 38: 613-618

Srinivas G, Satish K, Murali Mohan S, Nagaraja Reddy R, Madhusudhana R, Balakrishna D, Venkatesh Bhat B, Howarth CJ, Seetharama N. 2008. Development of genic-microsatellite markers for sorghum staygreen QTL using a comparative genomic approach with rice. Theor. Appl. Genet. 11: 283-296

Thomas H, Howarth CJ. 2000. Five ways to stay green. J. Exp. Bot. 51: 329-337

Valerio IP, Carvalho FIF Costa de Oliveira A, Benin G, Silveira G, Schmidt DAM, Stumpf MT, Woyann L. 2009. Seleção efetiva para o caráter número de afilhos em populações segregantes de trigo. Bragantia 68: 885-899

Vieira EA, Carvalho FIF, Costa de Oliveira A, Martins LF, Benin G; Silva JAG, Kopp MM, Hartwig I, Carvalho MF, Valério IP. 2007. Associação da distância genética em trigo estimada a partir de caracteres morfológicos, caracteres fenológicos e dos componentes do rendimento de grãos. Rev. Bras. Agrociência 13: 161-168 